\title{
Yapay Sinir Ağları ve Zaman Serileri Yöntemi ile Bir Endüstri Alanının (İvedik OSB) Elektrik Enerjisi İhtiyaç Tahmini

\author{
Araştırma Makalesi/Research Article
}

\author{
Semih ÖZDEN ${ }^{1} *$, Ali ÖZTÜRK ${ }^{2}$ \\ ${ }^{1}$ Elektronik ve Otomasyon, Teknik Bilimler MYO, Gazi Üniversitesi, Ankara, Türkiye \\ ${ }^{2}$ Elektrik - Elektronik Mühendisliği, Mühendislik Fakültesi, Düzce Üniversitesi, Düzce, Türkiye \\ semihozden@gmail.com, aliozturk@duzce.edu.tr \\ (Geliş/Received:12.03.2018; Kabul/Accepted:30.07.2018) \\ DOI: $10.17671 /$ gazibtd. 404250
}

\begin{abstract}
$\ddot{O}_{z}$ et—Özel firmalara enerji sağlayan firmalar veya işletmeler için enerji tüketiminin tahmini ve ihtiyaç planlaması çok kritiktir. Özellikle endüstri bölgelerindeki enerji ihtiyacı ev kullanıcılarının ihtiyacından daha yüksektir, bundan dolayı enerji ihtiyacının doğru tahminini gerektirir. Bu çalışmada, zaman serileri ve yapay sinir ağları olmak üzere iki farklı yaklaşım kullanılarak Türkiye'deki bir endüstri bölgesi için enerji ihtiyaç tahmini üzerinde çalışılmış ve sonuçlar test edilmiştir. Daha önceki çalışmalardan farklı olarak, kısıtlı veri ile kısa dönem tahmini için basit bir model geliştirilmiş̧ir. Model, giriş parametresi olarak geçmiş günlere ait tüketim verileri ve sıcaklığ içermektedir. Sıcaklık verisi, endüstri bölgelerinde ısıtma amaçlı enerji tüketiminde kullanıldığı için anahtar rol oynamaktadır. Zaman serileri yaklaşımında sadece geçmişe ait enerji tüketim verileri kullanılmıştır. Her iki yaklaşım enerji ihtiyaç tahmininde kullanılmış, sonuçlar tartışılmış ve karşılaştırılmıştır. Elde edilen sonuçlara göre; zaman serileri yöntemi R değeri 0.93901, yapay sinir ağları yöntemi R değeri 0.9859 elde edilmiştir. Zaman serileri yöntemi veri kısıtllğı sebebiyle yapay sinir ağlarına göre daha kötü bir tahmin gerçekleş̧irmiş̧ir.
\end{abstract}

Anahtar Kelimeler-Enerji tahmini, endüstri bölgesi, elektrik enerjisi, yapay sinir ağları, zaman serileri

\section{Electricity Energy Demand Forecasting for an Industrial Region (Ivedik) by using Artificial Neural Network and Time Series}

\begin{abstract}
Energy consumption prediction or demand planning is crucial for the energy supplier companies. Especially for industrial sites, the energy demand is higher than residential area, so it needs accurate forecasting of energy demand. In this study, two different approaches as time series and neural network were studied to forecast energy demand in an industrial area in Turkey and results were tested. Contrary to previous models / studies, a simple model was developed for short-term forecasting with limited data. The model involves energy consumption of previous days and temperature as input parameters. Temperature is key role for this industrial region to lead energy consumption for heating at the working places. Only previous days' energy consumption data were used in time series approach. These both approaches were performed in forecasting energy demand; results were discussed and compared. Depending on results, the result of $\mathrm{R}$ value for time series method is 0.93901 and the result of $\mathrm{R}$ value for neural network method is 0.9859 .
\end{abstract}

Keywords - Energy forecasting, industrial region, electricity energy, artificial neural network, time series

\section{GİRIŞ (INTRODUCTION)}

Kanunlar ve yönetmeliklerde yapılan değişikler sonrasında, Türkiye'de tüketiciler kendi elektrik enerjisini üretir veya bağımsız firmalardan satın alır hale gelmiştir. Özellikle, Organize Sanayi Bölgeleri (OSB) elektrik enerji ihtiyaçlarını özel firmalardan satın alarak karşılamaktadır. Bu çalışmada, Ankara ilinde bulunan OSTIM OSB'nin enerji tüketim verileri kullanılmış, tahmin modeli geliştirmeye çalışılmıştır. OSTIM OSB 5200 firması ve 6000 çalışanıyla büyük bir OSB konumdadır. Bu büyüklükte bir OSB için enerji ihtiyacının karşılanması ve planlanması çok önemli bir konudur. Doğru enerji tüketim tahmini, OSB firmalarının kullandığı elektrik enerjisi fiyatlarının düşmesine, daha kaliteli enerji teminine yardımcı olacağı kesindir. 
Literatürde, elektrik enerjisinin tahmini üzerine birçok çalışma bulunmaktadır. Neredeyse tüm makina öğrenme algoritmaları, modellenme teknikleri ve regresyon analizleri enerji tahmini için kullanılmıştır. Seçilen değişkenler ve veri yapısına göre metotların birbirine göre avantajları ve dezavantajları vardır. Enerji tüketiminin daha hassas tahmini için sadece enerji verileri değil aynı zamanda sosyal ve ekonomik parametreler de giriş değeri olarak kullanılmıştır. Mevcut çalışmalardan çıkan sonuçlara göre, Yapay Sinir Ağları (YSA) veya YSA tabanlı hibrit algoritmalar en çok tercih edilen ve en yakın tahmin modeli geliştirebilen yöntem olduğu görülmüştür.

Son ve Kim, destek vektör regresyonu ve bulanık tabanlı parçacık sürü algoritmasını kullanarak ev kullanıcılarının enerji tüketim verilerinin tahmini için bir model oluşturmuştur. Kuzey Kore için aylık enerji tüketimi, beş sosyal ve on dört meteorolojik değerler kullanılarak en düşük hata ile tahmin modeli geliştirilmiştir. Modeli eğitmek için, belirlenen değişkenlerin yirmi yıllık verileri kullanılmıştır [1]. Bir başka çalışmada, genetik algoritma yaklaşımı ile genel ve endüstri tabanlı enerji tüketiminin tahmini üzerine çalışılmıştır. Sadece ekonomik göstergeler (gayri safi milli hasıla, nüfus, ithalat ve ihracat) giriş parametresi olarak seçilmiştir [2]. Kialashaki ve Reisel, bir endüstri alanı için enerji ihtiyacının tahmininde YSA kullanmıştır. Geliştirilen model 1980 - 2012 yılları arasındaki veriler kullanılarak eğitilmiştir. Enerji fiyatları endüstrideki enerji tüketimini etkileyen en önemli faktör olduğu sonucuna varılmıştır [3]. Azadeh ve diğerleri İran'da endüstrinin y1llık enerji tüketiminin tahmini için YSA tabanlı bir model geliştirmiştir. Gerçek değerler ve klasik regresyon analiz yöntemlerinin sonuçları YSA ile karşılaştırılmış, YSA'nın üstünlüğü ortaya konulmuştur [4]. Bir başka YSA çalışmasında, Kuzey Kore için elektrik enerjisi talep modeli geliştirilmiş ve diğer regresyon analiz yöntemleri ile karşılaştırılmıştır [5]. Kumar ve Jain, üç farklı zaman serisi yaklaşımlarını kullanarak Hindistan'daki enerji tüketiminin tahmini gerçekleştirmiştir [6]. Mollaiy-Berneti, emperyalist rekabetçi algoritma ve geri yayılım algoritmalarını kullanarak hibrit bir model geliştirmiştir. Bu model, YSA'nın en uygun ağırlık ve bias değerlerinin bulunmasında kullanılmış, Türkiye ve Tayland ülkelerindeki enerji ihtiyaç tahmininde test edilmiştir [7]. Aynı yazarlar tarafindan yapılan bir başka çalışmada, sinirsel-bulanık bir sistem kullanarak hibrit bir algoritma geliştirilmiştir [8].

Birçok çalışma günlük ve aylık elektrik enerjisi tüketimi üzerine yapılmıştır. Bazı araştırmacılar ise daha hassas bir model geliştirmek için saatlik enerji tüketim verilerini kullanmıştır. Clements ve diğerleri gün içindeki yarım saatlik periyotlarla enerji tüketimi verilerini kullanarak zaman serileri yaklaşımıyla tahmin modeli geliştirmiştir [9]. Bir başka çalışma [10], saatlik enerji tüketimi verilerinin kullanımının daha doğru tahmin sağladığı sonucuna ulaşmıştır.

Türkiye için yapılan çalışmalarda, çok çeşitli algoritmalar sosyal, ekonomi ve geçmiş tüketim verileri kullanılarak elektrik ihtiyaç tahmini gerçekleştirilmiştir. Hamzacebi [11] YSA kullanarak net elektrik enerjisi tüketimini tahmin etmek için bir model geliştirmiş ve sonuçlar Türkiye'nin resmi enerji tahminleri ile karşılaştırılmıştır. Bir başka çalışmada, gri tahmin metodu elektrik enerjisi talep modellenmesinde kullanılmıştır [12]. Toksarı karınca sürü optimizasyon tekniğini kullanarak 2025 y1lına kadar olan enerji tahmini için bir model geliştirmiştir. Nüfus, gayri safi milli hasıla, ithalat ve ihracat verileri giriş parametresi olarak seçilmiştir [13]. Parçacık sürü optimizasyonu enerji tahmin modellemesi için tercih edildiği bu çalışmada, aynı giriş parametreleri kullanılmış ve diğer modellerle karşılaştırma yapılmıştır [14]. Türkiye'nin net elektrik enerji tüketim modellemesindeki bir diğer çalışma Sözen ve diğerleri tarafından gerçekleştirilmiştir. YSA ile geliştirilen farklı bağımsız değişkenlerin kullanıldığg ve test edildiği bu çalışmada, ekonomik parametreler (gayri safi milli hasıla ve gayri safi yurtiçi hasıla) enerji tüketiminin tahmininde daha doğru sonuç bulunmasını sağladığı görülmüştür [15,16]. 2010 yılında, Küçükali ve Barış bulanık mantığı kısa dönem yıllık enerji tüketim tahminine uygulamıştır [17]. Bilgili ve diğerleri, Türkiye'deki ev ve endüstri kullanıcıları için elektrik tüketim modellemesinde farklı metotlar üzerinde çalışmıştır. YSA, doğrusal ve doğrusal olmayan regresyon modellerinde giriş parametresi olarak kurulu enerji kapasitesi, elektrik üretim değerleri, nüfus ve toplam abone sayısı seçilmiştir. Elde edilen sonuçlara göre YSA diğer yöntemlere göre daha iyi sonuç vermiştir [18]. YSA, tahmin modeli geliştirme konusunda oldukça iyi sonuçlar vermektedir. Sadece enerji tahmini için değil mühendisliğin tüm branşlarında da tahmin edici olarak yapılan çalışmaların sayısı oldukça fazladır [19-21].

Literatürdeki çalışmalardan da anlaşılacağı üzere, yapay sinir ağları hem ev hem de endüstri üretim alanlarındaki tüketim değerlerinin tahmini için en iyi yöntemdir. $\mathrm{Bu}$ çalışmada da, YSA ve doğrusal olmayan (nonlinear) otoregresif sinir ağları (NOR-SA) kullanılmıştır. Daha önceki çalışmaların aksine, OSTIM OSB'ye ait kısıtlı bir veri paketi kullanılarak (sadece iki yıllık tüketim değerleri) basit bir model oluşturulmuştur. Bu sebeple, modelde sadece geçmişe ait enerji tüketim verileri ve sıcaklık kullanılmış, diğer karmaşık değerler ve modellerden kaçınılmıştır. Sıcaklık değerinin seçilmesindeki en önemli husus, genellikle KOBİ boyutundaki firmaların ısınma ihtiyacının elektrikli ısıtıcılardan sağlanmasıdır. Geliştirilen modelin doğruluğunu arttırmak için son üç günün ortalama tüketim değeri de giriş parametresi olarak eklenmiştir.

\section{YÖNTEM (METHODOLOGY)}

\subsection{Veri Paketi (Data Set)}

Çalışmada 2014 yılından 2016 yılına kadar olan toplamda 763 adet günlük enerji tüketim ve sicaklık verisi kullanılmıştır. Dini ve resmi tatiller, hafta sonu verileri kullanılmamış, sadece çalışma günleri göz önüne alınmıştır. Toplam verinin \%70'i YSA'nın eğitimi, \%15'i doğrulama ve $\% 15^{\prime} i$ test için ayrılmıştır. Tasarlanan 
tahmin modeli ve tüm algoritmalar MATLAB programı ile çalıştırılarak sonuca ulaştırılmıştır.

$\mathrm{Bu}$ çalışmada, özel bir endüstri bölgesinin enerji tüketiminin tahmininde basitleştirilmiş bir model geliştirilmesi üzerine çalışılmıştır. Sadece son iki yıla ait tüketim verileri kullanılarak algoritmaların eğitim süreci tamamlanmıştır. Son yıl test ve doğrulama amaçlı olarak ayrılmıştır. Tüketim verisinin günlere göre değişim grafiği Şekil 1'de gösterilmiştir.

YSA ve NOR-SA algoritmalarında kullanılmak üzere tüm giriş çıkış verileri Eşitlik 1' de verilen formül kullanılarak normalize edilmiştir.

$$
X_{\text {normalized }}=\frac{X-X_{\min }}{X_{\max }-X_{\min }}
$$

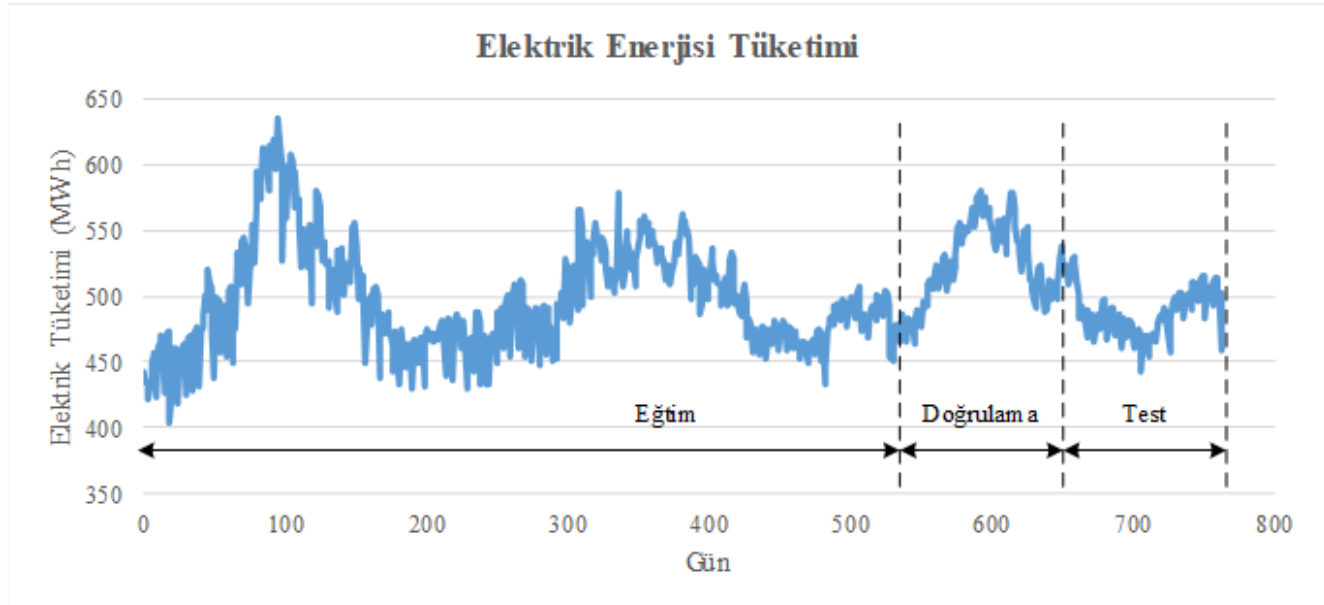

Şekil 1. OSTIM OSB için günlük elektrik tüketim grafiği (2014-2016)

(Daily electrical energy consumption plot of OSTIM ORIZ)

Tablo 1. YSA modelinin giriş parametreleri ve istatiksel analizi (Input variables of the ANN model and its statistical analysis)

\begin{tabular}{lrrrr}
\hline \multicolumn{1}{c}{ Değişken Adı (birimi) } & Ortalama & Std. Sapma & \multicolumn{1}{c}{ Asgari } & Azami \\
\hline Elektrik Tüketimi (MW) & 501.16 & 38.01 & 404.31 & 635.76 \\
Sicaklık $\left({ }^{\circ} \mathrm{C}\right)$ & 13.27 & 8.83 & -10.62 & 29.61 \\
Ortalama Elektrik Tüketimi (MW) & 501.15 & 36.39 & 427.62 & 629.12 \\
\hline
\end{tabular}

\subsection{Yapay Sinir Ağlarl (Artificial Neural Network)}

Tablo 1'de YSA için kullanılan verilerin istatiksel analizi görülmektedir. Geliştirilen YSA modelinde, geçmiş enerji tüketim verisi, sıcaklık ve son üç iş günündeki tüketim verilerinin ortalaması giriş parametreleri olarak seçilmiştir. $\mathrm{Bu}$ parametrelerin ortalama, standart sapma, azami ve asgari değerleri hesaplanarak tabloda sunulmuştur. Geliştirilen basitleştirilmiş YSA modeli Şekil 2'de gösterilmektedir.

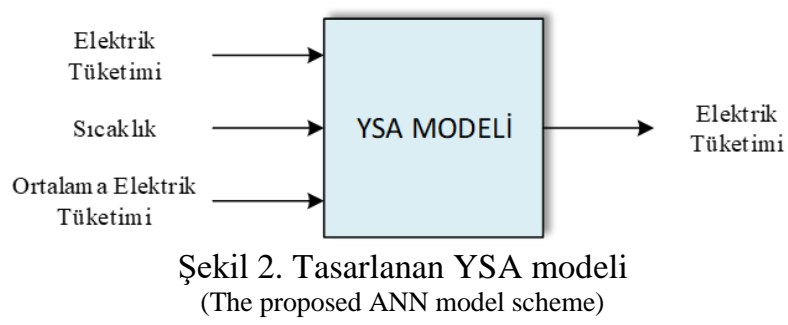

YSA modellemenin çıkış değeri Eşitlik 2' deki gibi hesaplanır.

$$
y=f\left(\sum_{i}^{n} x_{i} \omega_{i}+b\right)
$$

Burada, $y$ çıkışı, $n$ örnek sayısını, $f$ aktivasyon fonksiyonunu, $x_{i}$ girişi, $\omega_{i}$ nöronların ağırlık değerlerini ve $b$ ise bias değerini ifade etmektedir. A ğırlık ve bias değerleri çıkıştaki hata değerine göre güncellenerek hatanın azaltılması, sıfıra yaklaştırılması amaçlanmıştır.

\subsection{Zaman Serileri (Time Series)}

Zaman serileri, ileriye yönelik enerji ihtiyaç tahmininde tüketimin eğilimine göre sonuçlar sağlayan en basit modelleme yöntemidir [22]. Literatürde, birçok farklı tipte zaman serileri analiz yaklaşımları mevcuttur. $\mathrm{Bu}$ çalışmada, elektrik enerjisinin bir sonraki günde gerçekleşecek tüketim değerlerinin modellemesinde doğrusal olmayan (nonlinear) otoregresif sinir ağları 
(NOR-SA) tercih edilmiştir. Giriş verilerinin bu çalışmadaki gibi sayı olarak az olması zaman serilerinin bir zayıflığı olarak ortaya çıkmaktadır.

Modelin eğitim süreci zaman gecikmesi olarak adlandırılan geçmiş verilerle gerçekleştirilmiştir. Doğrusal olmayan otoregresif modellemenin matematiksel formülü Eşitlik 3'de sunulmuştur.

$$
y_{t}=\psi\left(y_{t-1}, \ldots \ldots, y_{t-n}\right)
$$

Burada, $y_{t}$ tahmin edilen veriyi, $\psi$ YSA yapısındaki ağ yapısını, $y_{t-n} n$ kadar gün önceki tüketim değerini göstermektedir. NOR-SA'nın yapısı Şekil 3'de gösterilmektedir. Gizli katman (hidden) yapısındaki 1:2 ifadesi kaç gün önceki değerin giriş parametresi olarak verildiğini göstermektedir. Bu değer yapılan uygulamaya ve veri tipine göre değişiklik göstermektedir. $\mathrm{Bu}$ çalışmada, farklı YSA katman sayıları ve gecikme değerleri kullanarak karşılaştırma yapılmıştır.

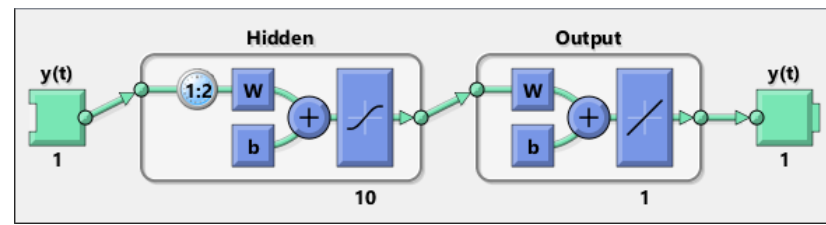

Şekil 3. NOR-SA'nın ağ yapısı

(The network structure of NAR-NN)

\section{SONUÇLAR (RESULTS)}

Tasarlanan modeller iki farklı ölçütle değerlendirilmiştir. Bunlardan ilki, tahmin edilen ile gerçek değer arasındaki yakınlığı ortaya koyan Ortalama Karesel Hata $(\mathrm{OKH})$ ölçütüdür. Bu değerin mümkün olduğu kadar küçük olması istenir ve formülü Eşitlik 4'te sunulmuştur.

$$
O K H=\frac{1}{n} \sum_{i}^{n}\left(y_{i}-y_{i}\right)^{2}
$$

Burada, $n$ örnek sayısını, $y_{i}$ gerçek değerleri, $y_{i}$ ise tahmin edilen değeri göstermektedir. Diğer değerlendirme ölçütü, bağıntı katsayısı (R) olarak seçilmiştir. Tahmin edilen değerlerin gerçek değerlerin oluşturduğu doğrusal çizgiye olan yakınlığını ortaya koyar. Eğer tahmin edilen ile gerçek değerler arasındaki fark küçükse, tasarlanan model iyi bir sonuç vermiş sayılır. Formülü Eşitlik 5'de verilmiştir.

$$
R=\frac{\sum_{i=1}^{n}\left(x_{i}-x\right)\left(y_{i}-y\right)}{\sqrt{\sum_{i=1}^{n}\left(x_{i}-x\right)^{2}} \sqrt{\left(y_{i}-y\right)^{2}}}
$$

\subsection{YSA Tahmin Modelinin Performansı (Performance of ANN Prediction Model)}

YSA ile tasarlanan modelin bir önceki bölümde verilen ölçütlere göre performans analizi Tablo 2'de verilmiştir. Model üç girişe bir çıkışa sahiptir. Farklı gizli katman sayıları hatayı küçültmek için test edilmiştir. Eğitim, doğrulama ve test için sonuçlar sunulmuştur. Ana değerlendirme ölçütü test verileri içindir, doğrulama ve eğitim, modelin eğitimi için kullanılmıştır. Hem R hem de OKH için en iyi değer 3-8-8-1 veya 3-8-1 ağ yapısı ile sağlanmıştır. Bu yapılardan, iki gizli katman ve her katmanda sekiz nörona sahip 3-8-8-1 yapısı için R eğrileri Şekil 4'de verilmiştir. (Eğitim: Training, Doğrulama: Validation, Test: Testing, Tümü: All, Hedef: Target)

\begin{tabular}{|c|c|c|c|}
\hline Katman Yapısı & Veri Tipi & $\mathbf{R}$ & ОКН \\
\hline \multirow{3}{*}{$3-6-6-1$} & Ĕ̆itim & 0.9688 & 0.0019 \\
\hline & Doğrulama & 0.9847 & 0.0005 \\
\hline & Test & 0.9436 & 0.0007 \\
\hline \multirow{3}{*}{ 3-8-8-1 } & Eğitim & 0.9700 & 0.0018 \\
\hline & Doğrulama & 0.9806 & 0.0006 \\
\hline & Test & 0.9443 & 0.0007 \\
\hline \multirow{3}{*}{$3-10-10-1$} & Eğitim & 0.9724 & 0.0017 \\
\hline & Doğrulama & 0.9730 & 0.0009 \\
\hline & Test & 0.9402 & 0.0007 \\
\hline \multirow{3}{*}{$3-12-12-1$} & Eğitim & 0.9714 & 0.0017 \\
\hline & Doğrulama & 0.9823 & 0.0006 \\
\hline & Test & 0.9360 & 0.0008 \\
\hline \multirow{3}{*}{$3-6-1$} & Eğitim & 0.9684 & 0.0019 \\
\hline & Doğrulama & 0.9858 & 0.0005 \\
\hline & Test & 0.9435 & 0.0007 \\
\hline \multirow{3}{*}{ 3-8-1 } & Eğitim & 0.9692 & 0.0018 \\
\hline & Doğrulama & 0.9849 & 0.0005 \\
\hline & Test & 0.9443 & 0.0007 \\
\hline \multirow{3}{*}{$3-10-1$} & Eğitim & 0.9698 & 0.0018 \\
\hline & Doğrulama & 0.9859 & 0.0005 \\
\hline & Test & 0.9380 & 0.0008 \\
\hline \multirow{3}{*}{$3-12-1$} & Eğitim & 0.9705 & 0.0018 \\
\hline & Doğrulama & 0.9827 & 0.0006 \\
\hline & Test & 0.9377 & 0.0008 \\
\hline
\end{tabular}

Tablo 2. YSA performans sonuçları (Performance result of the ANN) 

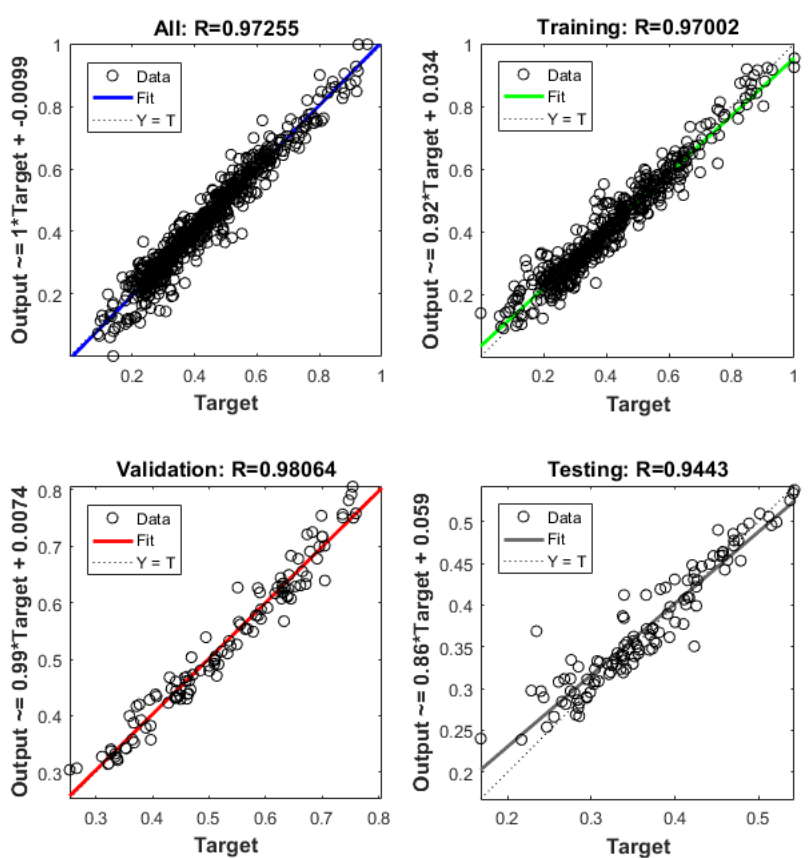

Şekil 4. YSA performansının R ile değerlendirmesi (The performance assessment of ANN by R)
3.2. NOR-SA Tahmin Modelinin Performansl (Performance of NAR-NN Prediction Model)

NOR-SA yaklaşımının performans değerlendirmesi Tablo 3 'de sunulmuştur. Altı farklı zaman gecikmesi, dört farklı ağ yapısı ile çalıştırılmış ve test edilmiştir. $\mathrm{R}$ için en iyi değer iki zaman gecikmeli 1-6-6-1 ağ yapısı ile elde edilmiştir. OKH için ise 0,0016 değeri beş farklı yapıda elde edilmiştir. İki zaman gecikmeli 1-6-6-1 ağ yapısı OKH değeri 0,0018 olarak hesaplanmıştır ve en yakın sonuca neredeyse eşittir. Enerji tüketiminin tahmin edilmesine geçmiş değerlerin çok büyük bir etkisi olduğu görülmüştür. İki zaman gecikmeli 1-6-6-1 yapısı için R eğrileri Şekil 5'de verilmiştir (Eğitim: Training, Doğrulama: Validation, Test: Testing, Tümü: All). Şekil 6'da gerçek değerler ile tahmin edilen değerlerin hem eğitim, doğrulama hem de test için grafikleri üst üste çizilerek sunulmuştur. Ayrıca oluşan hata grafiği şeklin altındaki grafiktir.

Tablo 3. NOR-SA performans sonuçları (Performance result of the NAR-NN)

\begin{tabular}{|c|c|c|c|c|c|c|c|c|c|}
\hline \multirow{2}{*}{$\begin{array}{c}\text { Zaman } \\
\text { Gecikmesi }\end{array}$} & \multirow{2}{*}{ Veri Tipi } & \multicolumn{2}{|c|}{$1-6-6-1$} & \multicolumn{2}{|c|}{$1-8-8-1$} & \multicolumn{2}{|c|}{$1-10-10-1$} & \multicolumn{2}{|c|}{$1-12-12-1$} \\
\hline & & $\mathbf{R}$ & OKH & $\mathbf{R}$ & OKH & $\mathbf{R}$ & OKH & $\mathbf{R}$ & OKH \\
\hline \multirow{3}{*}{2} & Eğitim & 0,90341 & 0,0056 & 0,90793 & 0,0053 & 0,90700 & 0,0054 & 0,90951 & 0,0054 \\
\hline & Doğrulama & 0,93901 & 0,0021 & 0,92983 & 0,0024 & 0,93503 & 0,0024 & 0,92942 & 0,0024 \\
\hline & Test & 0,83567 & 0,0018 & 0,83845 & 0,0019 & 0,82990 & 0,0020 & 0,82973 & 0,0019 \\
\hline \multirow{3}{*}{3} & Eğitim & 0,90954 & 0,0052 & 0,90674 & 0,0054 & 0,91235 & 0,0051 & 0,90983 & 0,0051 \\
\hline & Doğrulama & 0,92349 & 0,0025 & 0,93402 & 0,0022 & 0,92955 & 0,0026 & 0,92469 & 0,0025 \\
\hline & Test & 0,81475 & 0,0020 & 0,82955 & 0,0020 & 0,82555 & 0,0019 & 0,82220 & 0,0020 \\
\hline \multirow{3}{*}{4} & Eğitim & 0,90847 & 0,0052 & 0,91193 & 0,0050 & 0,91140 & 0,0051 & 0,91365 & 0,0050 \\
\hline & Doğrulama & 0,93165 & 0,0023 & 0,93132 & 0,0024 & 0,92492 & 0,0026 & 0,91979 & 0,0026 \\
\hline & Test & 0,82092 & 0,0019 & 0,81908 & 0,0020 & 0,81360 & 0,0020 & 0,80668 & 0,0021 \\
\hline \multirow{3}{*}{5} & Eğitim & 0,92806 & 0,0041 & 0,93236 & 0,0039 & 0,92494 & 0,0043 & 0,92555 & 0,0043 \\
\hline & Doğrulama & 0,91592 & 0,0026 & 0,92983 & 0,0022 & 0,92119 & 0,0024 & 0,92551 & 0,0024 \\
\hline & Test & 0,84057 & 0,0016 & 0,83892 & 0,0017 & 0,83498 & 0,0018 & 0,84142 & 0,0017 \\
\hline \multirow{3}{*}{6} & Eğitim & 0,93752 & 0,0036 & 0,93148 & 0,0039 & 0,93748 & 0,0036 & $\mathbf{0 , 9 3 7 7 3}$ & 0,0042 \\
\hline & Doğrulama & 0,90172 & 0,0029 & 0,91441 & 0,0026 & 0,91373 & 0,0026 & 0,90661 & 0,0023 \\
\hline & Test & 0,84644 & 0,0017 & 0,85370 & 0,0016 & 0,84667 & 0,0016 & 0,84176 & 0,0016 \\
\hline \multirow{3}{*}{7} & Eğitim & 0,92600 & 0,0043 & 0,93083 & 0,0039 & 0,92600 & 0,0043 & 0,93294 & 0,0041 \\
\hline & Doğrulama & 0,92149 & 0,0023 & 0,91805 & 0,0024 & 0,91428 & 0,0025 & 0,92079 & 0,0022 \\
\hline & Test & 0,83944 & 0,0017 & 0,85000 & 0,0016 & 0,83861 & 0,0017 & 0,84160 & 0,0017 \\
\hline
\end{tabular}



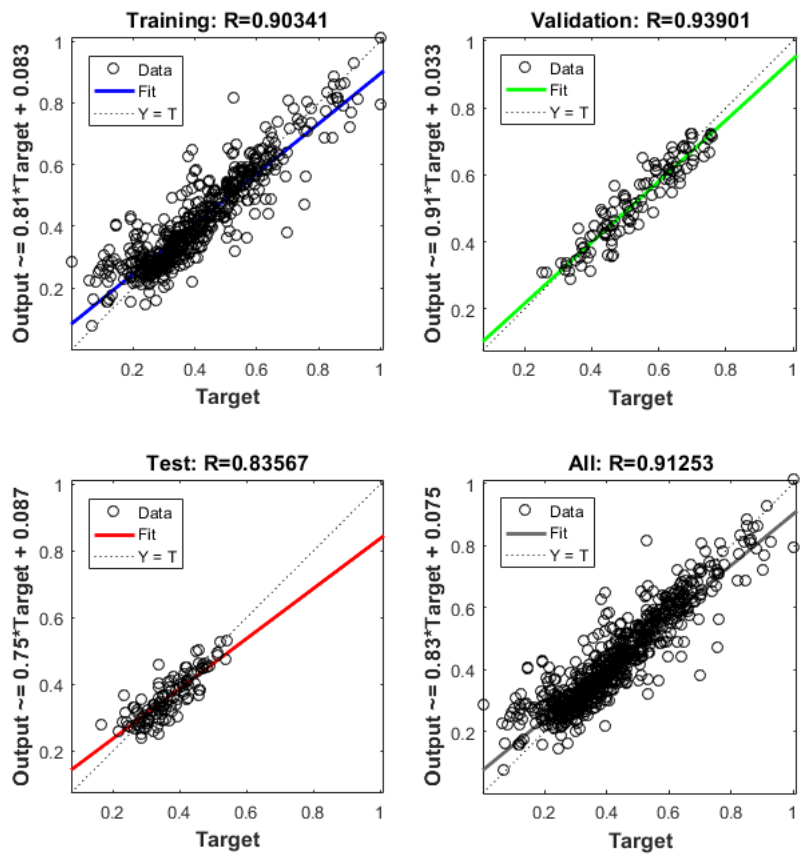

Şekil 5. NOR-SA performansının R ile değerlendirmesi (The performance assessment of NAR-NN by R)

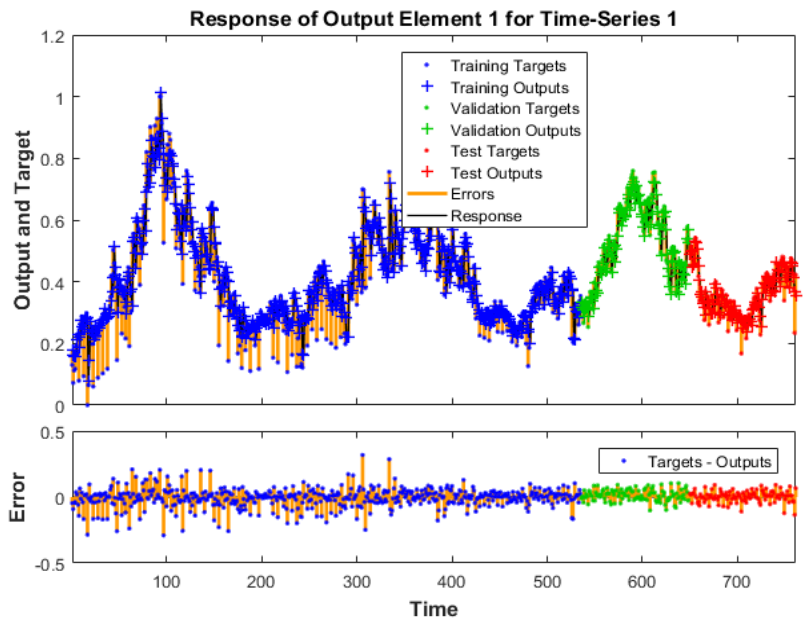

Şekil 6. YSA performansının R ile değerlendirmesi (The performance assessment of ANN)

\section{SONUCLARIN} (EVALUATION OF RESULTS)

DEĞERLENDİRILMESI

Çalışmada kullanılan yapay sinir ağları ve zaman serileri yöntemlerine ait sonuçlar bir önceki bölümde tablolar halinde sunulmuştur. Sonuçlar göz önüne alındığında tahmin modellerinden yapay sinir ağları daha yüksek performansla enerji tüketim verilerini tahmin etmiştir. Zaman serilerinin performansı, verinin sayısı ile doğrudan ilişkilidir ve bu sebeple daha kötü bir sonuç elde edilmiştir.

Literatürdeki mevcut çalışmalar, özel bir alanın enerji tüketim verileri yerine genellikle ülke / şehir tüketim verileri üzerine yapılmıştır. Bölgesel tüketim verilerinin çalışmalarda kullanılamamasının temel sebebi Türkiye gibi ülkelerin tüketim verilerinin bölgesel anlamda ayrıştırılmamış olmasıdır. Halbuki enerji piyasasındaki gelişmeler ile birlikte, çalışmadaki gibi özel alanların kendi enerji taleplerini, tüketim değerlerine göre özel şirketlerden karş1layabilecek duruma gelinmiştir. Bu sebeple bu alanların enerji taleplerini tahmin etmeleri aylık/yıllık enerji satın almalarının planlanması için önem arz etmektedir. Ancak, bu alanlara ait enerji tüketim verileri son birkaç yıldır kaydedilmeye başlanılmıştır ki çalışmanın kısıtlı bir veri ile yapılmasının ana sebebi budur. Önceki çalışmalarda kullanılan sosyal, ekonomik veriler bu çalışmada özellikle kullanılmamış, kısıtlı bir veri ile basit bir model geliştirilmeye çalışılmıştır. Yapılan çalışma da organize sanayilerin şu andaki gerçek bir problemin çözülmesi için gerçekleştirilmiştir.

\section{TEŞEKKÜR (ACKNOWLEDGMENTS)}

Bu çalışmada, tasarlanan modelde kullanılan meteorolojik verileri sağlayan Meteoroloji İşleri Genel Müdürlüğüne, enerji tüketim verilerini sağlayan Enerji Piyasaları İşletme A.Ş.' ye teşekkür ederiz.

\section{KAYNAKLAR (REFERENCES)}

[1] H. Son, C. Kim, "Short-term forecasting of electricity demand for the residential sector using weather and social variables", Resources Conservation and Recycling, 123, 200-207, 2017.

[2] H.K. Ozturk, H. Ceylan, "Forecasting total and industrial sector electricity demand based on genetic algorithm approach: Turkey case study", International Journal of Energy Research, 29(9), 829-840, 2005.

[3] A. Kialashaki, J.R. Reisel, "Development and validation of artificial neural network models of the energy demand in the industrial sector of the United States", Energy, 76(Supplement C), 749760, 2014.

[4] A. Azadeh, S.F. Ghaderi, S. Sohrabkhani, "Annual electricity consumption forecasting by neural network in high energy consuming industrial sectors", Energy Conversion and Management, 49(8), 2272-2278, 2008.

Z.W. Geem, W.E. Roper, "Energy demand estimation of South Korea using artificial neural network", Energy Policy, 37(10), 4049-4054, 2009.

[6] U. Kumar, V.K. Jain, "Time series models (GreyMarkov, Grey Model with rolling mechanism and singular spectrum analysis) to forecast energy consumption in India", Energy, 35(4), 1709-1716, 2010.

[7] S. Mollaiy-Berneti, "Developing energy forecasting model using hybrid artificial intelligence method", Journal of Central South University, 22(8), 3026-3032, 2015.

[8] S. Mollaiy-Berneti, "Optimal design of adaptive neuro-fuzzy inference system using genetic algorithm for electricity demand forecasting in Iranian industry", Soft Computing, 20(12), 48974906, 2016. 
[9] A.E. Clements, A.S. Hurn, Z. Li, "Forecasting dayahead electricity load using a multiple equation time series approach", European Journal of Operational Research, 251(2), 522-530, 2016.

[10] L.P.C. Do, K.-H. Lin, P. Molnár, "Electricity consumption modelling: A case of Germany", Economic Modelling, 55(Supplement C), 92-101, 2016.

[11] C. Hamzacebi, "Forecasting of Turkey's net electricity energy consumption on sectoral bases", Energy Policy, 35(3), 2009-2016, 2007.

[12] D. Akay, M. Atak, "Grey prediction with rolling mechanism for electricity demand forecasting of Turkey", Energy, 32(9), 1670-1675, 2007.

[13] M.D. Toksari, "Ant colony optimization approach to estimate energy demand of Turkey", Energy Policy, 35(8), 3984-3990, 2007.

[14] A. Unler, "Improvement of energy demand forecasts using swarm intelligence: The case of Turkey with projections to 2025", Energy Policy, 36(6), 1937-1944, 2008.

[15] A. Sozen, E. Arcaklioglu, "Prediction of net energy consumption based on economic indicators (GNP and GDP) in Turkey", Energy Policy, 35(10), 4981-4992, 2007.
[16] A. Sozen, E. Arcaklioglu, M. Ozkaymak, "Turkey's net energy consumption", Applied Energy, 81(2), 209-221, 2005.

[17] S. Kucukali, K. Baris, "Turkey's short-term gross annual electricity demand forecast by fuzzy logic approach", Energy Policy, 38(5), 2438-2445, 2010.

[18] M. Bilgili, B. Sahin, A. Yasar, E. Simsek, "Electric energy demands of Turkey in residential and industrial sectors", Renewable \& Sustainable Energy Reviews, 16(1), 404-414, 2012.

[19] H. Özkişi, M. Topaloğlu, "Fotovoltaik Hücrenin Verimliliğinin Yapay Sinir Ağı İle Tahmini", Bilişim Teknolojileri Dergisi, 10(3), 247-253, 2017.

[20] E. Çelik, O. Çavuşoğlu, H. Gürün, N. Öztürk, "Estimation of the Clearance Effect in the Blanking Process of CuZn30 Sheet Metal Using Neural Network-A Comparative Study", Bilişim Teknolojileri Dergisi, 11(2), 187-193, 2018.

[21] M. H. Calp, "İşletmeler için Personel Yemek Talep Miktarının Yapay Sinir Ağları Kullanılarak Tahmin Edilmesi", Politeknik Dergisi, DOI: 10.2339/politeknik.444380, 21(4), 2018.

[22] L. Suganthi, A.A. Samuel, "Energy models for demand forecasting-A review", Renewable \& Sustainable Energy Reviews, 16(2), 1223-1240, 2012. 